Earth Interactions - Volume 21 (2017) - Paper No. 1 • Page 1

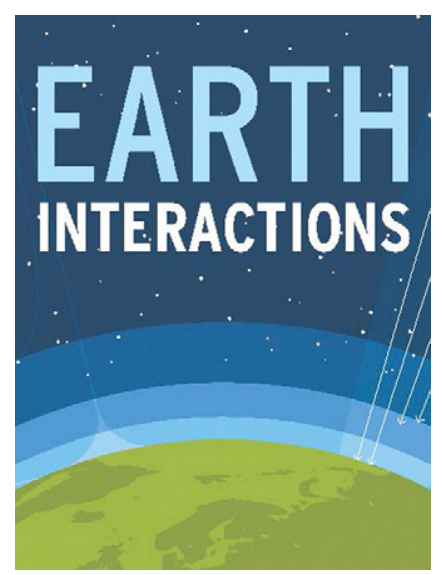

Copyright @ 2017, Paper 21-001; 67020 words, 4 Figures, 0 Animations, 5 Tables.

http://EarthInteractions.org

\title{
Short-Term Phenological Predictions of Vegetation Abundance Using Multivariate Adaptive Regression Splines in the Upper Colorado River Basin?
}

\section{Yuan Zhang ${ }^{\text {a }}$}

Institute of Remote Sensing and Digital Earth, Chinese Academy of Sciences, Beijing, China

\section{George F. Hepner}

Department of Geography, University of Utah, Salt Lake City, Utah

Received 12 June 2016; in final form 21 November 2016

\begin{abstract}
The accurate prediction of plant phenology is of significant importance for more sustainable and effective land management. This research develops a framework of phenological modeling to estimate vegetation abundance [indicated by the normalized difference vegetation index (NDVI)] 7 days into the future in the geographically diverse Upper Colorado River basin (UCRB). This
\end{abstract}

\footnotetext{
O Supplemental information related to this paper is available at the Journals Online website: http://dx.doi.org/10.1175/EI-D-16-0017.s1.

${ }^{\mathrm{a}}$ Corresponding author e-mail address: Yuan Zhang, zhangyuan76@126.com
}

DOI: 10.1175/EI-D-16-0017.1 
Earth Interactions - Volume 21 (2017) - Paper No. 1 • Page 2

framework uses phenological regions (phenoregions) as the basic units of modeling to account for the spatially variant environment-vegetation relationships. The temporal variation of the relationships is accounted for via the identification of phenological phases. The modeling technique of Multivariate Adaptive Regression Splines (MARS) is employed and tested as an approach to construct enhanced predictive phenological models in each phenoregion using a comprehensive set of environmental drivers and factors. MARS has the ability to deal with a large number of independent variables and to approximate complex relationships. The $R^{2}$ values of the models range from $91.62 \%$ to $97.22 \%$. The root-mean-square error values of all models are close to their respective standard errors ranging from 0.016 to 0.035 , as indicated by the results of cross and field validations. These demonstrate that the modeling framework ensures the accurate prediction of short-term vegetation abundance in regions with various environmental conditions.

KEYWORDS: North America; Vegetation-atmosphere interactions; Temperature; Remote sensing; Numerical analysis/modeling; Time series

\section{Introduction}

Plant phenology research studies how periodic biological phenomena of plants (phenological phases or phenophases) are influenced by environmental changes driven by weather and climate (Dahlgren et al. 2007; Schwartz 2003a; White et al. 1997). Accurate predictions of plant phenology and vegetation abundance, as a major research challenge in the field, are essential to many aspects in agriculture land management, livestock grazing, ecology, and fire risk assessment (Hodges 1991; Post and Inouye 2008; White et al. 1997).

The advent of remote sensing technology facilitates the evolution of phenological predictive modeling (phenomodeling). It provides a robust means to elevate the monitoring and modeling of plant phenological dynamics from individual plants and species to broadscale vegetation communities and ecosystems, thereby helping to improve the understanding of broadscale phenological trends, which are usually hard for traditional ground observations to detect. Remotely sensed plant phenology uses satellite imagery to track gradual plant growth and identify phenophases at regional, continental, and global scales (Xie et al. 2015). The normalized difference vegetation index (NDVI) has been widely used to assess plant phenology because the relationship between NDVI and vegetation abundance has been well established in literature (Ji and Peters 2004; Reed et al. 1994; White and Nemani 2006; Zhang et al. 2009; Zhang et al. 2001).

Phenological predictive models (phenomodels) refer to algorithms or quantitative expressions that simulate the responses of major plant physiological processes to environmental variables (Hodges 1991) in order to predict phenophases and vegetation abundance. Major advancements have been made in the development of quantitative phenomodels. These advancements include the addition of new environmental variables (Jolly et al. 2005; Pau et al. 2011), transition from predicting phenophase onsets to actual vegetation status (Ji and Peters 2004; Jolly et al. 2005), scaling-up from species and vegetation communities to ecosystems (Lin and Dugarsuren 2015), and use of more advanced modeling techniques ( $\mathrm{Ji}$ and Peters 2004). Phenology is influenced by a range of environmental variables. The increased dimensionality of data space leads to a series of problems such as multicollinearity, numerical instability, and overfitting, referred to as the "curse of dimensionality." 
Earth Interactions - Volume 21 (2017) • Paper No. 1 • Page 3

The environment-vegetation relationships are complex and spatiotemporally variant (Pau et al. 2011), making it hard to predict phenology accurately across location and time. Most phenomodels use a fixed set of environmental variables and model a fixed relationship pertinent to a specific study area, limiting the applicability of phenomodels to other regions.

This paper develops a short-term phenological predictive modeling framework that can be applied in regions with different physical settings to predict vegetation abundance 7 days in the future. The modeling technique of Multivariate Adaptive Regression Splines (MARS) introduced by Friedman (1991) is used. Unlike ordinary multivariate regression, MARS does not have to satisfy a lot of assumptions such as linear relationship, normal distribution, and homoscedasticity of residuals. It can deal with high dimensions of independent variables and is superior in flexibly approximating the complex, nonlinear, and nonmonotonic environment-vegetation relationships. This paper explains the application of MARS models to different phenological regions (phenoregions, phenologically and climatically self-similar clusters) in the Upper Colorado River basin (UCRB) for discussion. Individual MARS models are tuned for specific phenoregions. MARS models are validated using cross validation and field validation techniques. The results indicate that the MARS models yield accurate predictions under different physical settings.

\section{Methodology}

In this section, the study area of the UCRB and phenoregions in the UCRB are described. The partition of the geographically diverse UCRB into relatively homogeneous phenoregions accounts for the major spatial variations of environmentvegetation relationships. The major temporal variations of the relationships are accounted for by identification of phenophases. The MARS modeling technique is adopted to deal with the remaining nonlinearity of the relationships because it can flexibly model nonlinearity by fitting separate linear regression equations within different subregions of data space. The delineation of phenoregions, the identification of phenophases, and the adoption of MARS modeling technique enable the development of a well-performed phenomodel for each phenoregion. Figure 1 illustrates the MARS modeling framework for a phenoregion.

\subsection{Study area}

The UCRB (Figure 2) includes the watersheds that drain into the Colorado River system north of Lee's Ferry. The drainage area of the UCRB is over $290000 \mathrm{~km}^{2}$. The elevation ranges from approximately $1000 \mathrm{~m}$ in the southwest to $4000 \mathrm{~m}$ near the Uinta Mountains and southern Rockies. The complex topographic conditions in the UCRB cause the climate to exhibit different patterns. Such large tracts of land and extraordinary geographic diversity make the UCRB a worthwhile area for plant phenology to be examined and for a phenomodeling framework to be designed. This geographic diversity also makes the accurate prediction of vegetation abundance challenging.

Because of the geographic diversity in the UCRB, nine 1-km-pixel-based UCRB-specific phenoregions were delineated (Figure 2) in order to develop 


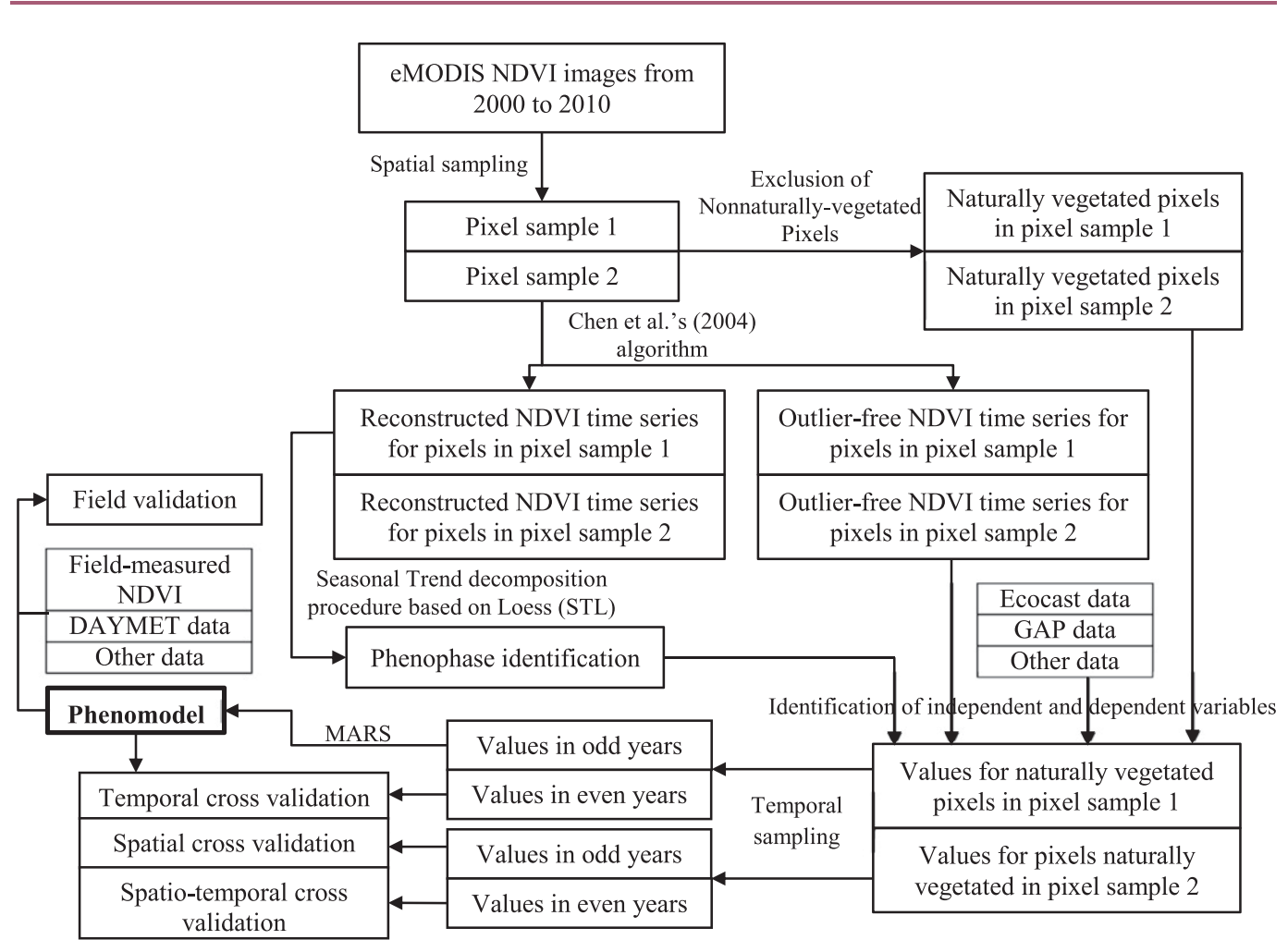

Figure 1. Premodeling and modeling procedure in a phenoregion.

phenoregion-specific models. Principal component analysis (PCA) combined with improved $k$-means clustering ( $k$-means ++ clustering) was used to differentiate environmental variables and generate phenoregions with similar phenological forcing. More details regarding the phenoregion delineation were described in Zhang et al. (2012). More homogeneous environment-vegetation relationships are expected in respective phenoregions (Hargrove and Hoffman 2004; White et al. 2005; Zhang et al. 2012). The vegetation composition and distribution in nine phenoregions are shown in Figures S1 and S2. Table S1 describes the phenoregionspecific mean elevation and climatic conditions.

\subsection{Data sources}

The onset and offset of phenophases can occur within a time window as short as only a few days. Data with lower temporal resolution will increase the uncertainty and difficulty in identification of phenophase onset/offset, and mask the accurate onset/offset date since all predictions are made for the next date after the 7-day interval. Data with higher temporal resolution are usually only available at much coarser spatial resolution (Cardot et al. 2008). Therefore, 1-km 7-day Earth Resources Observation and Science (EROS) Moderate Resolution Imaging Spectroradiometer (eMODIS) data are chosen as a trade-off. The 7-day composites from 2000 to 2010 , for a total count of 541, are used in this paper. The first 7-day 
Earth Interactions - Volume 21 (2017) • Paper No. 1 • Page 5

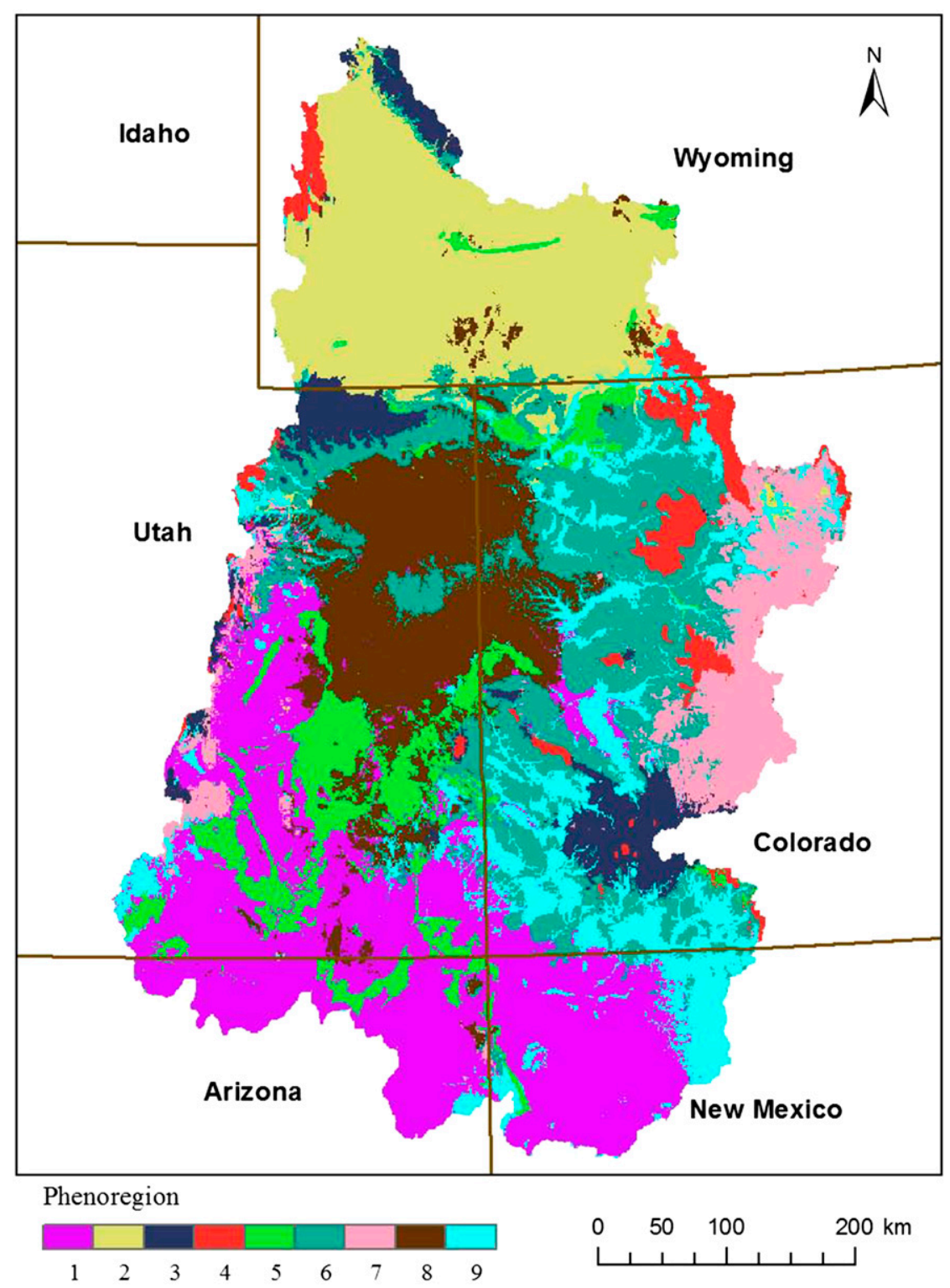

Figure 2. The UCRB study area and the nine phenoregions within the UCRB.

composite is from the 49th day to the 55th day of 2000, and the last is from the 173 rd day to 179 th day of 2010.

\subsection{1. eMODIS data}

The eMODIS product [U.S. Geological Survey (USGS)-EOS MODIS] is generated at the USGS's EROS Center. The eMODIS products provide the 7-day composite data at the spatial resolutions of $250 \mathrm{~m}, 500 \mathrm{~m}$, and $1 \mathrm{~km}$, including NDVI and surface reflectance bands over the continental United States. The 
Earth Interactions - Volume 21 (2017) • Paper No. 1 • Page 6

eMODIS products offer higher temporal resolution and faster production output than standard MODIS products (Jenkerson et al. 2010). The standard MODIS NDVI products are associated with geometric distortion in high-latitude regions far away from $0^{\circ}$ longitude, due to the sinusoidal projection designed for global coverage. The eMODIS NDVI products have significantly improved geometric features, while having a high agreement with the standard MODIS NDVI products (Ji et al. 2010). Therefore, eMODIS products are more suitable as the data source from which NDVI can be extracted.

\subsubsection{Ecocast data}

Ecocast data are the climate data product produced by the NASA Ames Ecological Forecasting Laboratory using the Terrestrial Observation and Prediction System (TOPS; NASA Ames Ecological Forecasting Laboratory 2009). The Ecocast gridded climatic dataset includes the maximum and minimum temperature, precipitation, and solar radiation. The Ecocast data were generated from the 49th day of 2000 to the 179th day of 2010 at $1 \mathrm{~km}$ over the study area of the UCRB by the NASA Ames Ecological Forecasting Laboratory. The temporal resolution is 7 days, and the compositing intervals are the same with those of the eMODIS data.

\subsubsection{GAP data}

National Gap Analysis Program (GAP) land-cover data at 30-m resolution is a seamless combination of the work of several different projects representing the ground land cover from 1999 to 2001 (USGS 2010). GAP data have three levels of details, from the most general of 8 classes to the most detailed of 75 classes within the study area of the UCRB. The 30-m, level-one classification is adopted to assist with the exclusion of nonnaturally vegetated pixels. It is resampled to $1-\mathrm{km}$ resolution using the majority resampling method and served as one of the independent variables in the phenomodels.

\subsubsection{Daymet data}

The Daymet dataset (Thornton et al. 2012) is a climatic dataset generated from the Daymet model by the Numerical Terradynamic Simulation Group (NTSG) at the School of Forestry, University of Montana. It is a 1-km dataset over regions of the United States, Mexico, Canada, Hawaii, and Puerto Rico and contains the variables of daily maximum and minimum temperature, precipitation, and solar radiation. It is available from 1 January 1980 to 31 December of the last calendar year. The Daymet data from the 123rd day to the 164th day of 2011 over the Upper Colorado River basin were used in field validation as the substitute of the Ecocast data, due to the unavailability of the Ecocast data during the period of field measurements.

\subsubsection{Other data sources}

The Digital Terrain Elevation Data (DTED) level 0 at 30 -arc-s $(\sim 1 \mathrm{~km})$ resolution compiled by the National Geospatial-Intelligence Agency (NGA; NGA $1996)$ in 2001 provides the elevation variable. Parameter-Elevation Regressions on 
Earth Interactions - Volume 21 (2017) • Paper No. 1 • Page 7

Independent Slopes Model (PRISM) dataset (PRISM Climate Group 2010) provides eight variables of long-term averages and seasonal variations of temperature and precipitation. A soil variability index (SVI) was calculated as the first principal component of the 10 soil parameters provided by the USGS compiled 1-km dataset of the State Soil Geographic (STATSGO) soil characteristics for the conterminous United States (USGS 1997). The mean annual NDVI is provided by the $1-\mathrm{km}$ dataset from the USGS by averaging the AVHRR-NDVI from 1990 to 2005.

\subsection{Premodeling preparations and analysis}

\subsubsection{Spatial and temporal sampling}

On the spatial dimension, stratified systematic sampling was adopted to extract pixels for modeling and cross validation. Stratified systematic sampling can effectively reduce spatial autocorrelation and ensure the independence of pixel samples. About one-twentieth of the total number of pixels in the UCRB was determined to be extracted. The sample size allocated to each phenoregion was calculated using Neyman allocation (Neyman 1934):

$$
n_{p}=n \frac{N_{p} \mathrm{SD}_{p}}{\sum_{i} N_{i} \mathrm{SD}_{i}},
$$

where $n_{p}$ is the sample size of phenoregion $p, n$ is the total sample size, $N_{p}$ is the number of pixels of phenoregion $p$, and $\mathrm{SD}_{p}$ is the standard deviation (heterogeneity) of phenoregion $p$. For each phenoregion, the sampled pixels were randomly divided into two sets: pixel sample one and pixel sample two. On the temporal dimension, values in odd years and in even years for the two pixel samples were extracted separately, creating four datasets (Figure S3 and Figure 1). Values of pixel sample one in odd years were used for model development (as training data). The other three datasets were used in temporal, spatial, and spatiotemporal cross validations (Fouillet et al. 2007; Muñoz-Díaz; Rodrigo 2006).

\subsubsection{Outlier exclusion}

The residual noise exists in the strictly preprocessed eMODIS NDVI product due to cloud contamination and poor atmospheric conditions. The noise tends to depress NDVI values. An iterated Savitzky-Golay filtering by Chen et al. (2004) was adopted to reconstruct the high-quality NDVI time series by approaching to the upper NDVI envelope progressively. The data points in the original NDVI time series that are far below the reconstructed time series are very likely to be less reliable and were thereby considered outliers and excluded from modeling.

\subsubsection{Identification of phenophases}

The purpose of phenophase identification is to partition a year into different temporal segments, during each of which the environment-vegetation relationships are expected to be more homogeneous. A diagram of the phenophase identification in a specific phenoregion is shown in Figure 3. The high-quality reconstructed 


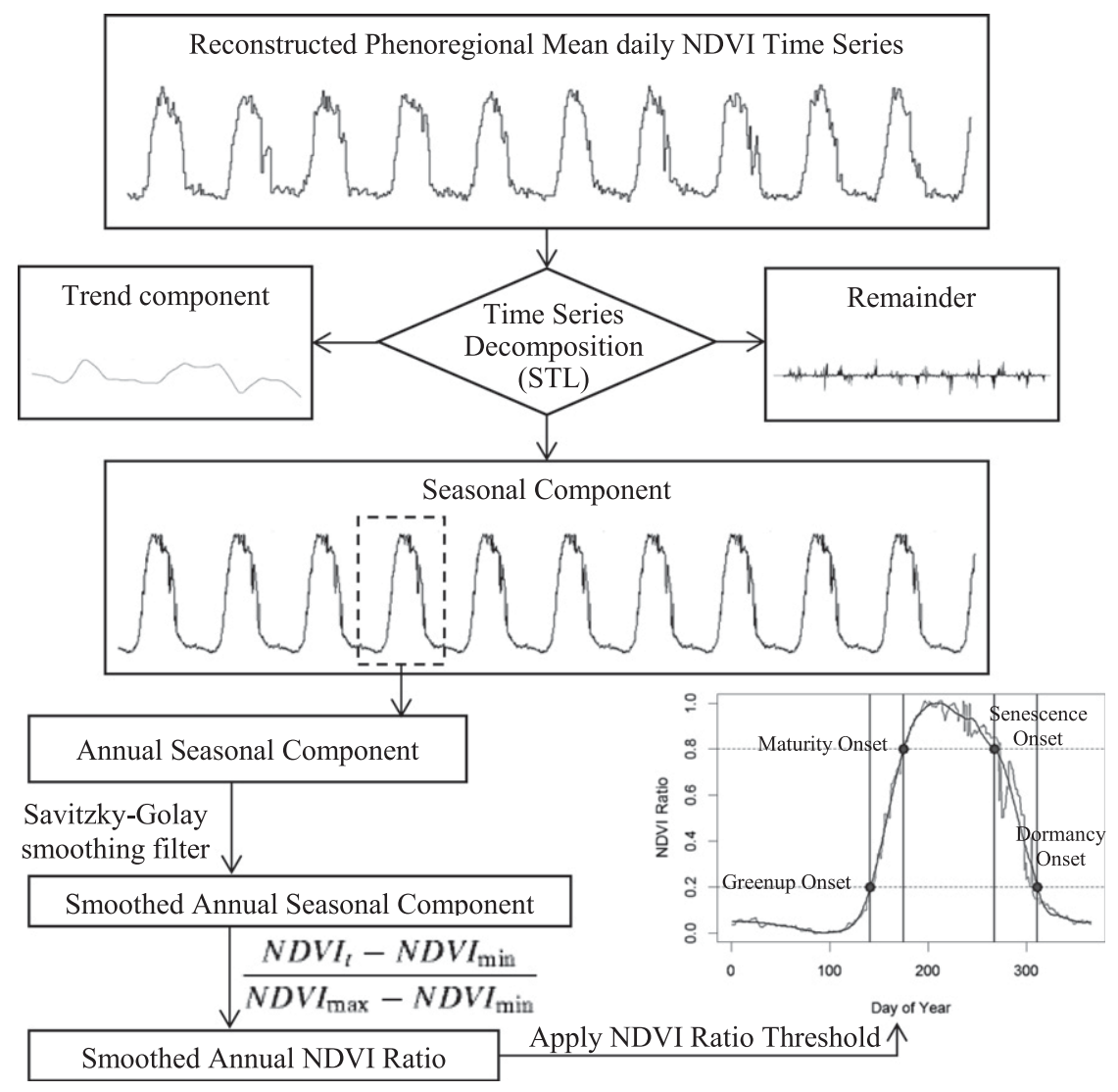

Figure 3. Diagram of phenophases identification.

NDVI time series of pixel sample one were averaged to compute the phenoregional mean time series, which can characterize the phenological cycle of that phenoregion as an integrated entity. A seasonal trend decomposition procedure based on Loess (STL; Cleveland et al. 1990) was adopted to decompose the phenoregional mean time series into three components: the trend component, the seasonal component (the cyclical component that roughly repeats itself at a certain frequency, representing seasonality), and the remainder. The identification of phenophases was conducted using the annual seasonal component. The annual seasonal component was smoothed using the Savitzky-Golay smoothing filter to further reduce noise and to achieve local monotonicity for derivation of reasonable phenophase onset dates. The NDVI values of the annual seasonal component were converted to NDVI ratio values (Kogan 1990) ranging from 0\% to $100 \%$ :

$$
\mathrm{NDVI}_{\text {ratio }}(t)=\frac{\mathrm{NDVI}_{t}-\mathrm{NDVI}_{\text {min }}}{\mathrm{NDVI}_{\text {max }}-\mathrm{NDVI}_{\text {min }}},
$$

where $\mathrm{NDVI}_{\text {ratio }}(t)$ is the NDVI ratio at time $t, \mathrm{NDVI}_{t}$ is the NDVI value at time $t$, and $\mathrm{NDVI}_{\max }$ and $\mathrm{NDVI}_{\min }$ are, respectively, the annual maximal and minimal values. The NDVI ratio normalizes for differences between different vegetation 
Earth Interactions - Volume 21 (2017) - Paper No. 1 • Page 9

covers while retaining temporal details. Therefore, the NDVI ratio thresholding method (White et al. 1997), as a dynamic thresholding method, was used in this paper to identify onset dates of four phenophases [greenup, maturity, senescence, and dormancy as described in Zhang et al. (2003)] in different phenoregions. The $20 \%$ and $80 \%$ of NDVI ratio were used as the thresholds, which can effectively avoid the mistaken use of the snowmelt onset as the greenup onset (Jonsson and Eklundh 2002; Shen et al. 2014; Tang et al. 2015; Van Leeuwen 2008; Yu et al. 2010). The phenophases were formed as a four-level categorical variable to partition the data space into subregions along with other independent variables. Different relationships can be modeled for different phenophases by including the variable of phenophases in a MARS model.

\subsubsection{Reduction of nonvegetative effects}

This paper focuses on plant phenology, so it is necessary to reduce nonvegetative effects on the data to avoid biased analysis and modeling results. First, the layer of sampled pixels was overlaid on the 30-m, GAP, land-cover map to derive the percentage of three level-one classes of "human land use," "aquatic," and "sparse and barren systems" combined; sampled pixels with a combined percentage of more than $50 \%$ were identified as nonnaturally vegetated pixels and were thereby excluded. Second, NDVI values of sampled pixels that were marked as snow in the eMODIS-NDVI images were removed. Third, NDVI values of sampled pixels below 0.1 were considered to contain no meaningful information in the context of plant phenology and were also removed.

\subsubsection{Dependent and independent variables}

Table 1 shows all 147 independent variables and their abbreviations. These independent variables were selected based on the environment-vegetation relationships summarized in the literature.

The NDVI values of different 7-day intervals were used as the dependent variable of phenomodels to represent vegetation abundance. The antecedent NDVI values (NDVI_1), that is, the correspondent NDVI values of previous 7-day composites relative to the dependent variable, were included in the models as one of the independent variables because the antecedent status of vegetation influences the current environment-vegetation relationships (Ji and Peters 2004; Piao et al. 2006). By including the lagged dependent variable (LDV), the models were specified as dynamic models to represent how past NDVI values gradually develop into current NDVI values as influenced by the environment.

Temperature, precipitation, and light directly "drive" plant development (Fitter et al. 1995; Peñuelas et al. 2004; Prins and Loth 1988; Reed et al. 1994; Sparks and Carey 1995; Sparks et al. 1997; Sparks et al. 2000; White et al. 1997) and thereby are referred to as environmental drivers in this paper.

Temperature is one of the major factors that control plant activity, phenological cycles, and plant distribution (Badeck et al. 2004; Fitter et al. 1995; Sparks and Carey 1995; Sparks et al. 2000). In general, higher temperatures within the optimal temperature range can accelerate plant development, leading to earlier phenophase onsets. Common temperature measures include mean (TMEAN), minimum 


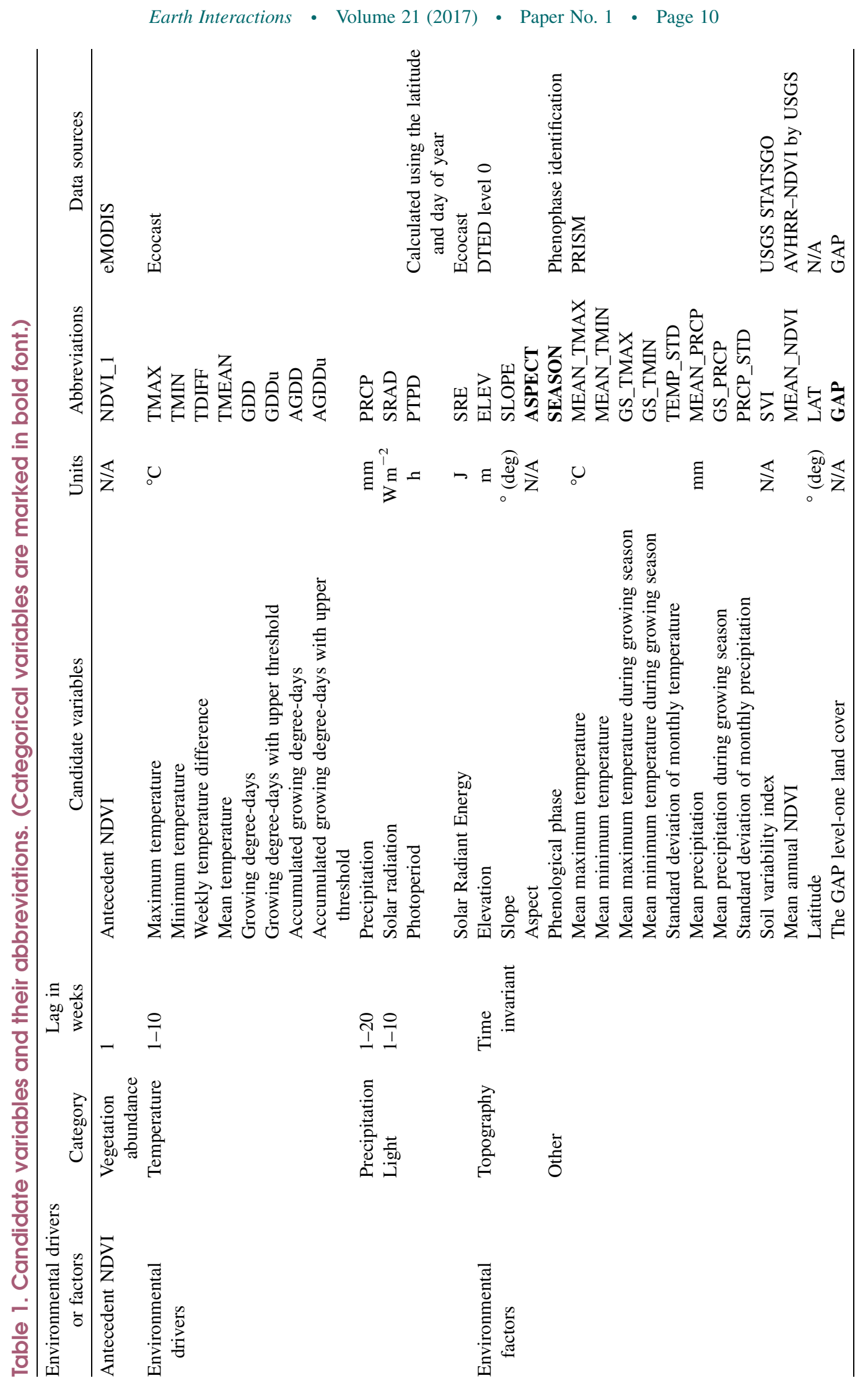


(TMIN), and maximum temperature (TMAX; Schwartz 2003b). The weekly temperature difference (TDIFF) was also included as one of the independent variables because it has a favorable effect on plant growth (Larcher 2003). Growing degree-days (GDD) is another common temperature measure used in phenological research. Some studies used besides a base temperature an upper temperature threshold in the calculation of GDD because there is also a heat limit beyond which plant development will stop or become much slower. The accumulated growing degree-days (AGDD) accumulate the GDD from a consistent starting date. Some studies indicated that AGDD is linearly related to plant growth and development (Miller et al. 2001; Villordon et al. 2009). Therefore, GDD, GDD with an upper threshold (GDDu), and the accumulated values of these two variables (AGDD and AGDDu) starting from the first day of each year were also included. TMAX and TMIN were extracted directly from Ecocast data, and other temperature variables were calculated based on TMAX and TMIN.

The relationship between precipitation and plant growth is complicated because the amount of water and how water is used is dependent on precipitation forms (rain or snow), soil conditions, vegetation types, phenophases, and evapotranspiration activities influenced by temperature and such. Although temperature has much greater influence on plant phenology during most of the time and at most locations, precipitation is of greater importance in moisture-limited regions because water stress strongly restricts phenological development and plant production (Bruns et al. 2003; Lambers et al. 2008; Moulin et al. 1997; Peñuelas et al. 2004; Pickup et al. 1994; Reed et al. 1994). The variables of precipitation (PRCP) were extracted from Ecocast data.

Many phenological events are associated with light as a signal (Sharma 2005; Srivastava 2002; Timmermans 2010). Both the intensity and duration of light influence plant development, so solar radiation (SRAD) from Ecocast data and photoperiod (PTPD) calculated using latitude and day of year were included in the light category. Solar radiant energy (SRE), the product of SRAD and PTPD, was also included.

It has been shown that vegetation responds to all environmental drivers in a lagged way, and the length of the lag is generally longer for precipitation as opposed to temperature and light (Cui et al. 2009; Davenport and Nicholson 1993; Estrella et al. 2007; Gessner et al. 2013; Menzel 2003). Antecedent values of environmental drivers are important factors influencing the timing of phenophases. Based on the lag time recorded in literature, temperature and light variables were chosen to lag 1 to 10 weeks and precipitation variables were chosen to lag 1 to 20 weeks to account for the lagged responses of vegetation. The antecedent NDVI and variables of environmental drivers were named with suffixes of the number of lags in weeks (such as TMAX_1 through TMAX_10).

As opposed to environmental drivers, environmental factors are time-invariant variables. As part of the physical settings, they moderate the influence of environmental drivers on the 7-day vegetation dynamics and account for the interpixel and interphenophase difference of environment-vegetation relationships. The effects of landscape, specifically elevation, slope, and aspect, on vegetation are very pronounced in the natural environment (Batanouny 2001; Campbell 1974; Henebry 2003; Schuster et al. 1989; Sharma 2005). Soil characteristics cause plant growth and distribution to vary (Waugh 2000). Phenology exhibits a latitudinal gradient 
Earth Interactions - Volume 21 (2017) • Paper No. 1 • Page 12

due to the influence of latitude on light and temperature (Ahrens 2007; Jorgensen 2009; Van Dyke 2008). Environment-vegetation relationships also vary among phenophases and vegetation types (Larcher 2003; Pfafflin and Ziegler 2006; Pugnaire and Valladares 1999; Wielgolaski and Inouye 2003). Topographic variables, soil conditions (SVI), phenophases (SEASON, formed as a four-level categorical variable), latitude (LAT), and the GAP level-one land cover (GAP) were therefore included as independent variables. The long-term averages and seasonal variations of temperature and precipitation (MEAN_TMAX, MEAN_TMIN, GS_TMAX, GS_TMIN, TEMP_STD, MEAN_PRCP, GS_PRCP, and PRCP_STD) characterize local climatic patterns and are determinant factors of the spatial distribution of vegetation cover and vegetation density (Suzuki et al. 2000; Walter and Wieser 1973; Whittaker 1970; Woodward 1987). They were also included as an important part of environmental factors. The growing season was defined as from the greenup onset to the dormancy onset. Categorical variables are marked in bold font in Table 1.

\subsection{Development of phenomodels}

\subsubsection{Multivariate adaptive regression splines}

In reality, vegetation-environment relationships are complex. They vary across locations and seasons. The interaction between variables further complicates the relationships. The complex relationships are extremely difficult to quantify. The MARS approach was adopted in this research to conduct model development. MARS is a nonparametric regression technique that has been applied to model complex relationships and deal with high dimensions of independent variables (Balshi et al. 2009; Chou et al. 2004; Friedman 1991). MARS does not require assumptions about the linear relationships between the dependent and independent variables. Instead, MARS is composed of a series of "basis functions" that model the relationships within different subregions of data space. Essentially, MARS is an extension to the linear regression in the form of piecewise regression. The piecewise nature of MARS makes it especially appropriate in modeling the complex vegetation-environment relationships. MARS performs well in dealing with large datasets, making it a suitable modeling approach in the context of remote sensing phenomodeling.

The MARS model takes the form of

$$
Y=\beta_{0}+\sum_{i=1}^{k} \beta_{i} B_{i}(X)
$$

where $Y$ is the dependent variable, $B_{i}(X)$ is a basis function, and $k$ is the number of basis functions included in the MARS model. A basis function $B_{i}(X)$ (Figure $\mathrm{S} 4$ ) is a two-sided truncated function (main effects) or the product of several truncated functions (interaction terms) in the form

$$
\max (0, x-c) \text { i.e., } \begin{cases}x-c, & \text { if } x>c \\ 0, & \text { otherwise }\end{cases}
$$

or 


$$
\begin{aligned}
& \text { Earth Interactions } ・ \text { Volume } 21(2017) \cdot \text { Paper No. } 1 \cdot \text { Page } 13 \\
& \max (0, c-x) \text { i.e., } \begin{cases}c-x, & \text { if } x<c \\
0, & \text { otherwise }\end{cases}
\end{aligned}
$$

or

$$
\max \left(0, x_{i}-c_{i}\right) \times \max \left(0, x_{j}-c_{j}\right),
$$

where $x$ is an independent variable and $c$ is the location of the "knot" or breakpoint. Adjacent splines are connected smoothly at the knot, resulting in the flexibility of MARS to represent complex relationships.

The development of MARS models includes two phases: the forward and the backward pass. The forward pass tends to build an overfit model as with other nonparametric models due to their adaptability. The backward pass then uses pruning techniques to simplify the model and increase the performance of its generalization to the prediction of new datasets. The two passes ensure that the most important environmental drivers and factors as well as their interactions were selected within respective subregions in the data space (Friedman 1991; Friedman and Roosen 1995).

MARS has been successfully used in building statistical models for prediction and classification in many fields. Balshi et al. (2009) used MARS to predict burned area; Leathwick et al. (2006), Elith and Leathwick (2007), and Stohlgren et al. (2010) uses MARS to predict and model species distribution. Despite all the advantages and the suitability of MARS to model the complex vegetation dynamics, few studies have used it in phenological predictions. This research is among the first attempts to use MARS in phenomodeling.

\subsubsection{Modeling procedure}

The environmental drivers and factors are highly correlated, referred to as multicollinearity. Although MARS is robust to the violation of many assumptions required by ordinary multivariate regression models, multicollinearity is a serious concern. This research used a variance inflation factor (VIF)-based approach to iteratively remove variables until the VIF values of all remaining independent variables are below 10 . The multicollinearity was thereby greatly reduced by feeding only a subset of all independent variables into the MARS models.

Values of pixel sample one in odd years were used as the training data to build phenomodels. MARS models were built using the package "Earth" in R (R Core Team 2015). Figure 4 shows how values were extracted from images of environmental factors and images of NDVI and environmental drivers on all dates in odd years and used as dependent and independent variables in the phenomodels. A unique phenomodel was built for each of the nine phenoregions using the MARS approach.

All variables were divided into two categories: The first category includes all time-variant environmental drivers. This category directly drives the development of vegetation abundance from NDVI_1 to NDVI within 1 week. Variables in this category also influence how vegetation responds to other variables within this same category. The other category includes the time-invariant environmental factors and 
NDVI_1. These variables adjust the influence of variables in the first category on plant development. Therefore, the phenomodels take the form:

$$
\begin{aligned}
\mathrm{NDVI}= & \sum_{i} a_{i} \mathrm{ED}_{i}+\sum_{i j} b_{i} \mathrm{ED}_{i} \times \mathrm{EF}_{j}+\sum_{i j}^{i \neq j} c_{i} \mathrm{ED}_{i} \times \mathrm{ED}_{j} \\
& +\sum_{i} d_{i} \mathrm{ED}_{i} \times \mathrm{NDVI}_{-} 1+\sum_{i} e_{i} \mathrm{EF}_{i}+f \times \mathrm{NDVI} 1+\varepsilon,
\end{aligned}
$$

where ED represents environmental drivers and EF represents environmental factors. The practical meaning can be more clearly seen if we change the equation above to

$$
\begin{aligned}
\mathrm{NDVI}= & \left(\sum_{i} a_{i}+\sum_{i j} b_{i} \mathrm{EF}_{j}+\sum_{j} c_{i} \mathrm{ED}_{j}+\sum_{i} d_{i} \times \mathrm{NDVI} \_1\right) \\
& \times \sum_{i} \mathrm{ED}_{i}+\sum_{i} e_{i} \mathrm{EF}_{i}+f \times \mathrm{NDVI}_{-} 1+\varepsilon .
\end{aligned}
$$

The first component in (8) indicates the influence of a specific environmental driver $\mathrm{ED}_{i}$ on the development of vegetation abundance from the value of NDVI_1 to the value of NDVI. This influence is dependent on the NDVI value in the previous week (NDVI_1), environmental factors, and other environmental drivers, explicitly $\left(\sum_{i} a_{i}+\sum_{i j} b_{i} \mathrm{EF}_{j}+\sum_{j} c_{i} \mathrm{ED}_{j}+\sum_{i} d_{i} \times \mathrm{NDVI}_{-} 1\right)$. Statistically, this expression (the influence of $\mathrm{ED}_{i}$ on the 7-day vegetation dynamics) is composed of the main effect as well as the effect moderated by environmental factors, other environmental drivers, and NDVI_1 in the order they appear in the expression. The second component $\left(\sum_{i} e_{i} \mathrm{EF}_{i}\right)$, statistically the main effect of the environmental factors, works as the minor adjustment on NDVI accounting for the interpixel and interphenophase difference of the environment-vegetation relationships.

The performance of the phenomodels built using MARS was quantified by two measures: $R^{2}$ and the standard error. The $R^{2}$ quantifies the amount of variance in the dependent variable that can be accounted for by the independent variables in the model specification. The standard error measures the accuracy of the model by quantifying the mean deviation of the fitted values from the observed values.

\subsection{Model validations}

\subsubsection{Cross validation}

Cross validation applies the models in other independent datasets in order to assess the models' performance and prediction accuracy. For each phenoregion, the model was applied on values of pixel sample two in odd years for spatial cross validation, on values of pixel sample one in even years for temporal validation, and on values of pixel sample two in even years for spatiotemporal validation. The three kinds of cross validation were adopted to avoid overfitting and to ensure the models can be generalized both temporally and spatially.

For each type of cross validation in a phenoregion, two measures of fit were used to quantify how accurately the phenomodels predict. Root-mean-square error 
Earth Interactions - Volume 21 (2017) • Paper No. 1 • Page 15

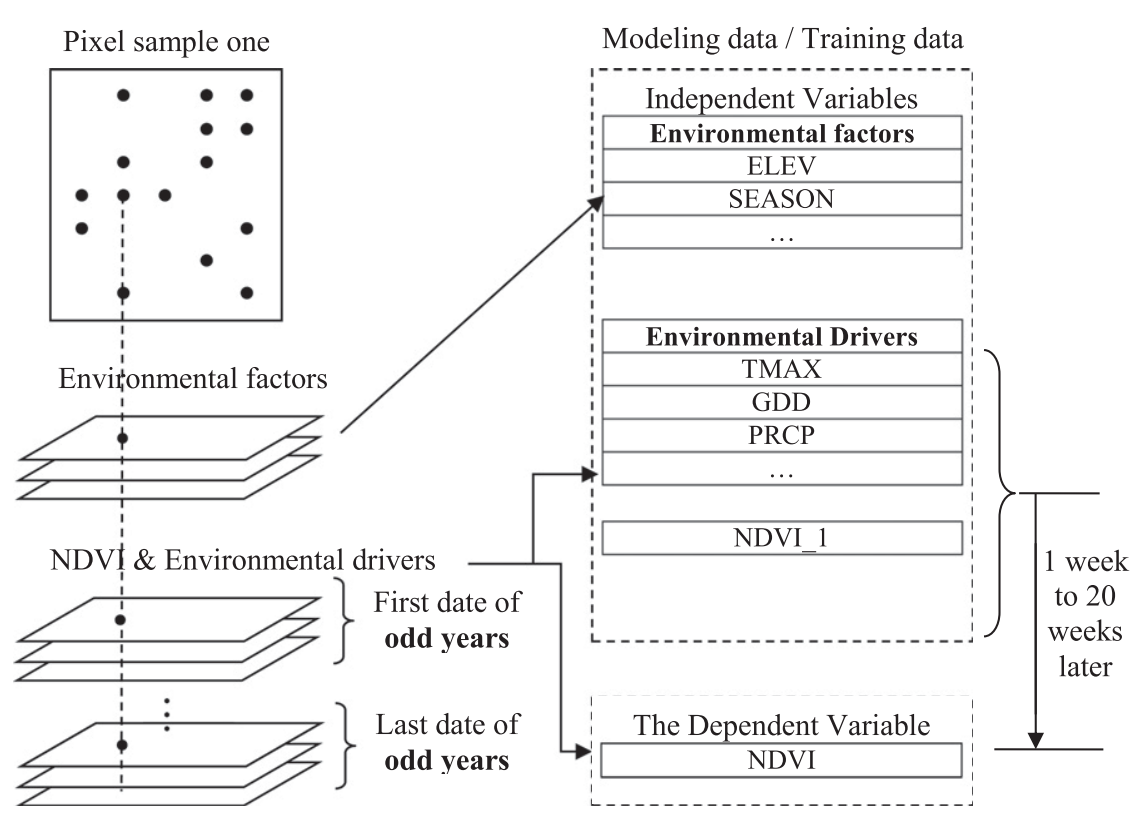

Figure 4. Transformation from the pixel sample to modeling data (training data).

(RMSE) measures differences between predicted values and observed values (prediction errors). RMSE is calculated as

$$
\operatorname{RMSE}=\sqrt{E\left[\left(Y_{\text {pred }}-Y_{\mathrm{ob}}\right)^{2}\right]},
$$

where $Y_{\text {pred }}$ is the predicted value, and $Y_{\mathrm{ob}}$ is the observed value. The coefficient of variation $(\mathrm{CV})$, or the RMSE normalized to the mean of the observed values, is a relative measure of prediction accuracy and is independent of the unit of the dependent variable. The $\mathrm{CV}$ is calculated as

$$
\mathrm{CV}=\frac{\mathrm{RMSE}}{\overline{Y_{\mathrm{ob}}}}
$$

The CV is usually expressed as a percentage, which makes it easier to compare the accuracy of the models across different phenoregions and datasets.

\subsubsection{Field validation}

The field validation is to ensure that the phenomodels are capable of practical application. For ease of repeated spectral measurements for weeks, field work was conducted in a region west of Duchesne, Utah, clustered with patches of different phenoregions. Three field sites within an acceptable distance to major roads were selected respectively from three phenoregions (phenoregions 2, 8, and 9). Consistent per week spectra measurements were conducted at three field sites from late April to early June 2011, using an analytical spectral device (ASD) full-range field 
Earth Interactions • Volume 21 (2017) • Paper No. 1 • Page 16

spectrometer. At each field site, a 45-m-long transect with randomly extending direction was selected in order to make sure that the average NDVI measured along this transect could represent the NDVI of the $1-\mathrm{km}^{2}$ pixel the field site is in. During each measurement, spectra of 16 points equally distributed along the $45-\mathrm{m}$ transect every $3 \mathrm{~m}$ were measured five times at nadir. The field sites in phenoregions two and eight were measured consecutively for seven weeks: 27 April, 4 May, 13 May, 21 May, 27 May, 3 June, and 10 June 2011. The field site located in phenoregion nine was covered by snow until 21 May, so it was only measured for four weeks, from 21 May to 10 June 2011. The measurements on 21 May 2011 were less reliable because of the overcast sky and variant light conditions and therefore are excluded from field validation. In spectra processing, the radiance data were converted to reflectance, and NDVI was calculated using the averaged reflectance over the MODIS spectral response function for the red band $(620-670 \mathrm{~nm}$ ) and near-infrared band (841-876 nm), consistent with the range of bands one and two of MODIS.

The Daymet data were used as a substitute data source of Ecocast data for providing the environmental drivers. The 1-km daily Daymet dataset was either averaged (solar radiation and maximum and minimum temperature) or accumulated (precipitation) over the seven 7-day intervals of field measurements. The field measured NDVI serves as the dependent variable of NDVI during these 7-day intervals as well as the independent variable of antecedent NDVI during the corresponding previous 7-day intervals. The predicted NDVI values were compared with the field measured NDVI values. Similarly with cross validation, the prediction power of the models can also be quantified using the RMSE and $\mathrm{CV}$.

\section{Results and discussion}

Nine phenological predictive models were built for the nine phenoregions in UCRB, respectively, using the MARS approach. Table 2 shows the values of $R^{2}$ and standard error of the phenomodels in the nine phenoregions. All nine MARS models have good performance with a range of the largest $R^{2}$ of $97.22 \%$ in phenoregion 6 and the lowest $R^{2}$ of $91.62 \%$ in phenoregion 1 . This indicates that for all models, a very high percentage of variances in NDVI can be explained by the antecedent NDVI and the phenoregion-specific set of environmental drivers and factors. All nine models also have high accuracy as indicated by the standard errors.

\subsection{Validation results}

The results of cross validation as quantified by RMSE and CV are shown in Table 3. The RMSE values of all models are close to their respective standard errors, indicating the successfulness of the models in generalization to temporally and spatially independent data in respective phenoregions. The CV values enable the comparison of prediction accuracy across phenoregions. Table 3 shows that phenoregion 4 has the best performance in all three types of cross validation, followed by phenoregions 3,6 , and 7. 
Earth Interactions - Volume 21 (2017) - Paper No. 1 • Page 17

Table 2. The $R^{2}$ and standard error of phenomodels in the nine phenoregions.

\begin{tabular}{cccc}
\hline Phenoregion & No. of cases for modeling & $R^{2}$ & Standard error \\
\hline 1 & 85673 & $91.62 \%$ & 0.016 \\
2 & 85948 & $95.25 \%$ & 0.019 \\
3 & 14922 & $95.40 \%$ & 0.035 \\
4 & 13742 & $96.13 \%$ & 0.034 \\
5 & 31348 & $93.54 \%$ & 0.016 \\
6 & 80060 & $97.22 \%$ & 0.028 \\
7 & 23960 & $96.23 \%$ & 0.034 \\
8 & 69174 & $95.94 \%$ & 0.022 \\
9 & 53111 & $96.65 \%$ & 0.025 \\
\hline
\end{tabular}

The RMSE and CV values of the field validation (Table 4) tend to be slightly larger than those of the cross validation in phenoregion 2 , while those are smaller in phenoregions 8 and 9. This difference is the combined results of different data sources' (Daymet instead of Ecocast), errors during field measurements and the representativeness of point samples of areal coverages of satellite pixels. The RMSE and CV values of the field validation in all three phenoregions are within reasonable ranges as compared to those in cross validation in spite of the difference.

As indicated by the results of cross validation and field validation, the MARS models have comparably high accuracy when applied in new independent datasets and in practical applications.

\subsection{Influence of environmental variables on vegetation dynamics}

The MARS models include a range of 8 to 13 independent variables in different phenoregions (Table 5). The variable of antecedent NDVI ranks first in all phenoregions because the current NDVI values are developed from the past NDVI values as influenced by the environment.

Temperature variables are included in the models of all nine phenoregions. The variables of accumulated growing degree-days (AGDD and AGDDu) are of greater

Table 3. The RMSE of the temporal, spatial, and spatiotemporal cross validations in the nine phenoregions.

\begin{tabular}{|c|c|c|c|c|c|c|c|c|c|c|}
\hline \multirow[b]{2}{*}{ Phenoregion } & \multirow[b]{2}{*}{ Standard error } & \multicolumn{3}{|c|}{$\begin{array}{c}\text { Temporal cross } \\
\text { validation }\end{array}$} & \multicolumn{3}{|c|}{$\begin{array}{c}\text { Spatial cross } \\
\text { validation }\end{array}$} & \multicolumn{3}{|c|}{$\begin{array}{l}\text { Spatiotemporal } \\
\text { cross validation }\end{array}$} \\
\hline & & $\begin{array}{c}\text { No. of } \\
\text { cases }\end{array}$ & RMSE & $\begin{array}{l}\mathrm{CV} \\
(\%)\end{array}$ & $\begin{array}{c}\text { No. of } \\
\text { cases }\end{array}$ & RMSE & $\begin{array}{l}\mathrm{CV} \\
(\%)\end{array}$ & $\begin{array}{c}\text { No. of } \\
\text { cases }\end{array}$ & RMSE & $\begin{array}{l}\mathrm{CV} \\
(\%)\end{array}$ \\
\hline 1 & 0.016 & 59897 & 0.016 & 8.2 & 98648 & 0.016 & 8.1 & 70638 & 0.017 & 8.3 \\
\hline 2 & 0.019 & 60759 & 0.020 & 9.1 & 88826 & 0.018 & 8.9 & 61944 & 0.020 & 9.3 \\
\hline 3 & 0.035 & 10320 & 0.039 & 8.1 & 15032 & 0.035 & 7.3 & 10129 & 0.039 & 8.3 \\
\hline 4 & 0.034 & 8567 & 0.037 & 6.6 & 13909 & 0.034 & 5.9 & 8812 & 0.037 & 6.5 \\
\hline 5 & 0.016 & 24369 & 0.017 & 7.9 & 37895 & 0.017 & 7.8 & 28430 & 0.017 & 8.0 \\
\hline 6 & 0.028 & 62289 & 0.029 & 7.9 & 81451 & 0.028 & 7.1 & 62273 & 0.029 & 7.8 \\
\hline 7 & 0.034 & 16963 & 0.034 & 7.7 & 24052 & 0.034 & 7.2 & 17258 & 0.035 & 7.8 \\
\hline 8 & 0.022 & 55058 & 0.022 & 8.9 & 73051 & 0.023 & 8.5 & 60503 & 0.023 & 9.1 \\
\hline 9 & 0.025 & 44070 & 0.025 & 8.1 & 62447 & 0.026 & 7.7 & 52828 & 0.027 & 8.2 \\
\hline
\end{tabular}


significance than weekly temperature variables (e.g., TMAX, TMIN and GDD) according to the variable importance rankings shown in Table 5 and Tables S2 through S10. This indicates that temperature, especially accumulated temperature, is very important in accounting for 7-day vegetation dynamics. Precipitation variables are included in the MARS models in seven out of nine phenoregions. The ranks of precipitation variables are generally lower than those of temperature variables. This indicates that the temporal variance in precipitation is not as important as that in temperature in driving plant growth and development. Precipitation variables at much shorter lags (1 to 5 weeks) and much longer lags (16 to 20 weeks) appear to be more important in the UCRB than those at intermediate lags, since only phenoregions 1 and 5 include the latter type into their phenomodels (PRCP_10 for phenoregion 1 and $\mathrm{PRCP}_{-} 7$ for phenoregion 5). The UCRB contains both fast-responding, shallow-rooted shrubs and grasses and slow-responding forest and deep-rooted shrubs. Soil permeability plays an important role influencing root-zone soil moisture available for slow-responding vegetation (Yang et al. 1997). Phenoregions 1 and 5 have higher soil permeability (USGS 1997), so rainfall can reach the soil faster, resulting in the inclusion of precipitation at intermediate lags in the phenomodels. Light variables are also considered important in plant development but are less commonly included in equivalent models in literature. The SRAD variables are the only kind of light variables that are included in phenomodels. Most of the PTPD and SRE variables are removed because of multicollinearity beforehand.

Latitude is one of the most important environmental factors because it is included in five models and has higher ranks than temperature variables in phenoregions 1 and 5. Phenoregions 1 and 5 cover a larger range of latitudes, requiring the inclusion of LAT to explain the spatial variation of environment-vegetation relationships. Phenophase (SEASON) is also a very important environmental factor, included in models of all phenoregions except for phenoregion 1. Three categories of phenophases are included in phenomodels. The category maturity is included in seven out of nine phenoregions, indicating a different environment-vegetation relationship in the maturity phase. However, this does not indicate that the vegetationenvironment relationships are consistent in other phenophases. The application of MARS, by modeling different relationships within different subregions of data space, partly accounts for the temporally variant relationship and weakens the influence of phenophases as shown in models. Long-term averages and seasonal variations of environmental drivers are also very important, with mean annual NDVI (MEAN_NDVI) being the most important one. MEAN_NDVI is included in models of all phenoregions with high ranks. This indicates that the plant development as influenced by environmental drivers is greatly affected by the spatial variation of vegetation abundance.

It can be observed from the results that vegetation responds faster to environmental drivers in dryer phenoregions and phenoregions with more shrubland and grassland (Tables 5 and S1, and Figures S1 and S2). This is inferred from the fact that environmental drivers at shorter lags are more likely to be selected to enter the model in such phenoregions. For example, temperature variables at shorter lags are more important in phenoregions 1, 5, and 6; precipitation variables at shorter lags are considered more important in phenoregions 1, 5, and 7. Also, some phenoregions containing more shrubland (such as phenoregion 5) include both 
Earth Interactions Volume 21 (2017) • Paper No. 1 • Page 19

Table 4. The RMSE and CV of field validation.

\begin{tabular}{ccc}
\hline Phenoregion & RMSE & CV \\
\hline 2 & 0.028 & $9.1 \%$ \\
8 & 0.015 & $5.6 \%$ \\
9 & 0.016 & $4.8 \%$ \\
\hline
\end{tabular}

environmental drivers at shorter and longer lags. This is probably caused by the mixed species of slow-responding forest and deep-rooted shrubs and fastresponding, shallow-rooted shrubs and grasses.

Environmental drivers are found to be more important in phenoregions where they are limiting factors. Precipitation is more important in moisture-limited phenoregions such as phenoregions 1 and 5 (Table S1), which have both the largest number of precipitation variables and main-effect precipitation variables. Temperature is more important in cooler phenoregions. For example, the phenoregions 3, 4, 6, and 7 with lower temperatures (Table S1) have the main-effect temperature variables. Solar radiation is more important in phenoregions 2, 3, 4, and 7. These phenoregions generally have a significant portion located in the northern part of the UCRB as compared with other phenoregions and therefore receive less solar radiation.

\section{Discussion and conclusions}

This research developed a modeling framework to make short-term phenological predictions for the geographically diverse UCRB. A key component of phenomodeling is the simulation of the vegetation responses under different combinations of environmental drivers and factors, so that the model performs well across time and location. The MARS modeling technique is used in this research to build more realistic representations of the 7-day vegetation dynamics as influenced by environmental variations. The good performance of phenomodels in nine phenoregions in the UCRB with different physical settings demonstrates the success of MARS in making accurate, short-term, phenological predictions in regions with various environmental conditions.

\subsection{Applicability and restrictions of MARS modeling framework}

The MARS modeling framework uses the geographically diverse UCRB as the study area, so it can generalize to other regions without or with only minor modifications. The list of candidate variables used in this research was summarized from literature on various regional settings and therefore makes a comprehensive set. The MARS modeling approach is flexible enough to select the most important variables and to approximate complex vegetation-environment relationships. Therefore, the phenoregion delineation plus the MARS modeling framework presented in this research can also be applied to other geographically diverse regions and to homogeneous regions with different physical settings.

The complexity of the responses of vegetation to the environment in the UCRB results in the advantages of more flexible MARS over ordinary linear regression. MARS does not assume linear relationships, normal distribution, and 


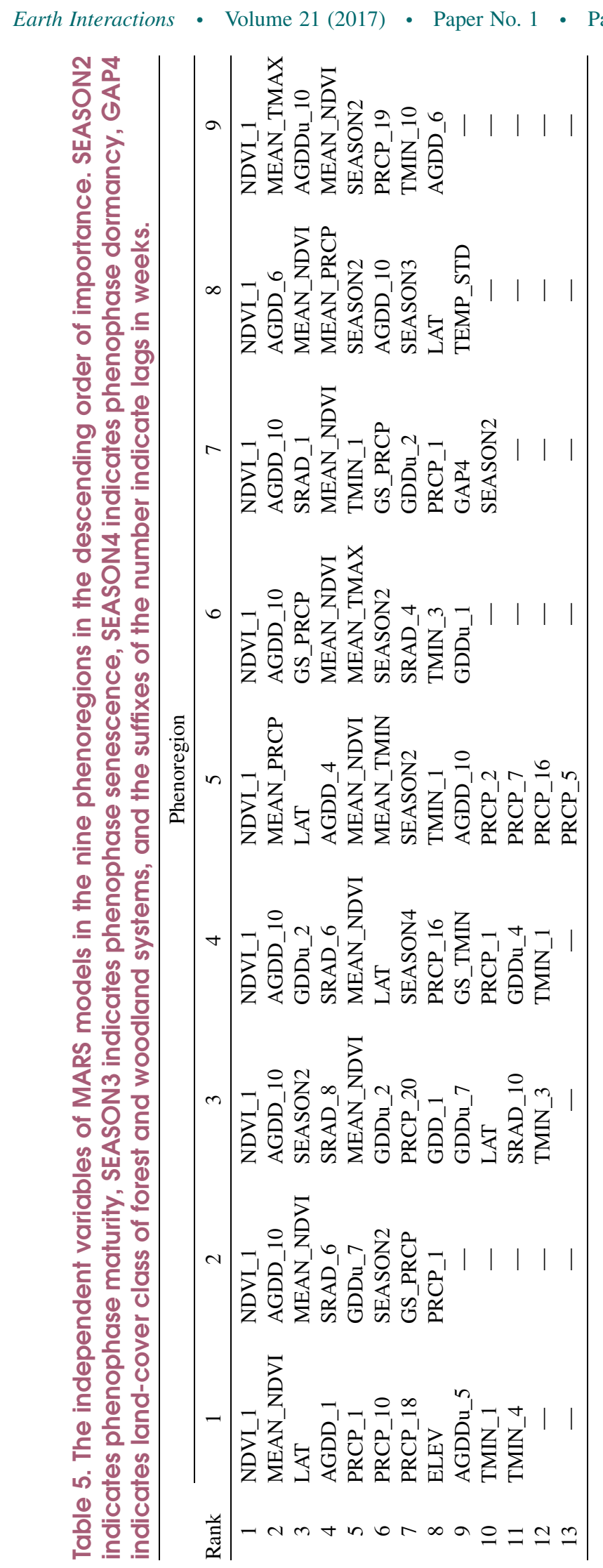


Earth Interactions - Volume 21 (2017) • Paper No. 1 • Page 21

homoscedasticity of residuals. It can approximate any kind of relationships using basis functions driven by data. MARS is easily interpretable, as with linear regression. MARS is much faster than other nonlinear regression methods, while predictive performance of MARS is comparable to nonlinear methods (Elith and Leathwick 2007).

Valid use of the MARS approach requires a very large number of observations. Second, the confidence intervals of parameters cannot be calculated directly for MARS models, and certain validation techniques are required to validate the models. Therefore, the MARS modeling is not the optimal approach when the number of observations is small and when field validation cannot be conducted.

\subsection{The dependent variable of phenomodels}

Rather than phenophase onset dates, the models developed in this paper predict vegetation abundance (as indicated by NDVI) 7 days in the future (Boke-Olén et al. 2016; Hermance et al. 2015; Jolly et al. 2005). This can greatly reduce the uncertainty introduced by variant NDVI time series smoothing methods and phenophase onset date extraction methods. Repetitive predictions of NDVI can form continuous vegetation abundance estimates throughout the year. The phenophase onset dates predicted by traditional phenomodels can be derived by thresholding the predicted NDVI.

\subsection{Contributions}

This research substantiates phenological theory by disentangling the complex and spatiotemporally variant environment-vegetation relationships. It evaluates impacts of single and multiple environmental variables on 7-day vegetation dynamics in different phenoregions and phenophases. The results showed that faster response of vegetation can be observed in dryer phenoregions and phenoregions with more shrubland and grassland. Environmental drivers are more important in phenoregions where they are limiting factors. Vegetation responds to the environment in a much more different way in the phenophase of maturity. Methodologically, a multilayer and multifaceted modeling framework was designed to make accurate short-term predictions of vegetation abundance in geographically diverse regions. The modeling framework can deal with the curse of dimensionality, flexibly model complex environment-vegetation relationships, and can be applied to other regions. The more accurate short-term vegetation abundance prediction can assist with many fields, such as fire risk assessment, rangeland management/livestock grazing, agriculture, and ecology (Castro et al. 2003; Hodges 1991; Post and Inouye 2008; White and Nemani 2006).

Acknowledgments. This research was supported by a U.S. Bureau of Land Management Grant "Predicting Phenological Plant Stages in the Upper Colorado Basin." The authors thank the U.S. Bureau of Land Management for financial support; Dr. Ramakrishna Nemani, Forrest Melton, and Andrew Michaelis; the Ecological Forecasting Lab at NASA Ames Research Center for Ecocast data support; and Drs. Bruce Wylie from USGS Earth Resources Observation and Science Center and Heidi Hadley from the U.S. 


$$
\text { Earth Interactions - Volume } 21 \text { (2017) - Paper No. } 1 \text { • Page } 22
$$

Bureau of Land Management for support and guidance. The authors also thank the two anonymous reviewers whose comments and suggestions greatly improved the manuscript.

\section{References}

Ahrens, C. D., 2007: Meteorology Today: An Introduction to Weather, Climate, and the Environment. Thomson/Brooks/Cole, 624 pp.

Badeck, F.-W., A. Bondeau, K. Böttcher, D. Doktor, W. Lucht, J. Schaber, and S. Sitch, 2004: Responses of spring phenology to climate change. New Phytol., 162, 295-309, doi:10.1111/ j.1469-8137.2004.01059.x.

Balshi, M. S., A. D. McGuire, P. Duffy, M. Flannigan, J. Walsh, and J. Melillo, 2009: Assessing the response of area burned to changing climate in western boreal North America using a Multivariate Adaptive Regression Splines (MARS) approach. Global Change Biol., 15, 578600, doi:10.1111/j.1365-2486.2008.01679.x.

Batanouny, K. H., 2001: Plants in the Deserts of the Middle East. Springer, 193 pp.

Boke-Olén, N., V. Lehsten, J. Ardö, J. Beringer, L. Eklundh, T. Holst, E. Veenendaal, and T. Tagesson, 2016: Estimating and analyzing savannah phenology with a lagged time series model. PLoS One, 11, e0154615, doi:10.1371/journal.pone.0154615.

Bruns, E., F.-M. Chmielewski, and A. J. H. Vanvliet, 2003: The global phenological monitoring concept. Phenology: An Integrative Environmental Science, M. D. Schwartz, Ed., Tasks for Vegetation Science Series, Vol. 39, Springer, 93-104.

Campbell, R. K., 1974: Use of phenology for examining provenance transfers in reforestation of Douglas-fir. J. Appl. Ecol., 11, 1069-1080, doi:10.2307/2401766.

Cardot, H., P. Maisongrande, and R. Faivre, 2008: Varying-time random effects models for longitudinal data: Unmixing and temporal interpolation of remote-sensing data. J. Appl. Stat., 35, 827-846, doi:10.1080/02664760802061970.

Castro, F. X., A. Tudela, and M. T. Sebastià, 2003: Modeling moisture content in shrubs to predict fire risk in Catalonia (Spain). Agric. For. Meteor., 116, 49-59, doi:10.1016/ S0168-1923(02)00248-4.

Chen, J., P. Jönsson, M. Tamura, Z. Gu, B. Matsushita, and L. Eklundh, 2004: A simple method for reconstructing a high-quality NDVI time-series data set based on the Savitzky-Golay filter. Remote Sens. Environ., 91, 332-344, doi:10.1016/j.rse.2004.03.014.

Chou, S.-M., T.-S. Lee, Y. E. Shao, and I. F. Chen, 2004: Mining the breast cancer pattern using artificial neural networks and multivariate adaptive regression splines. Expert Syst. Appl., 27, 133-142, doi:10.1016/j.eswa.2003.12.013.

Cleveland, R. B., W. S. Cleveland, J. E. McRae, and I. Terpenning, 1990: STL: A seasonal-trend decomposition procedure based on Loess. J. Off. Stat., 6, 3-33.

Cui, L., J. Shi, Y. Yang, and W. Fan, 2009: Ten-day response of vegetation NDVI to the variations of temperature and precipitation in eastern China. Acta Geogr. Sin., 64, 850-860.

Dahlgren, J., L. Oksanen, M. Sjödin, and J. Olofsson, 2007: Interactions between gray-sided voles (Clethrionomys rufucanus) and bilberry (Vaccinium myrtillus), their main winter food plant. Oecologia, 152, 525-532, doi:10.1007/s00442-007-0664-8.

Davenport, M. L., and S. E. Nicholson, 1993: On the relation between rainfall and the normalized difference vegetation index for diverse vegetation types in East Africa. Int. J. Remote Sens., 14, 2369-2389, doi:10.1080/01431169308954042.

Elith, J., and J. Leathwick, 2007: Predicting species distributions from museum and herbarium records using multiresponse models fitted with multivariate adaptive regression splines. Diversity Distrib., 13, 265-275, doi:10.1111/j.1472-4642.2007.00340.x.

Estrella, N., T. H. Sparks, and A. Menzel, 2007: Trends and temperature response in the phenology of crops in Germany. Global Change Biol., 13, 1737-1747, doi:10.1111/ j.1365-2486.2007.01374.x. 


\section{Earth Interactions - Volume 21 (2017) • Paper No. 1 • Page 23}

Fitter, A. H., R. S. R. Fitter, I. T. B. Harris, and M. H. Williamson, 1995: Relationships between first flowering date and temperature in the flora of a locality in central England. Funct. Ecol., 9, 55-60, doi:10.2307/2390090.

Fouillet, A., G. Rey, E. Jougla, P. Frayssinet, P. Bessemoulin, and D. Hémon, 2007: A predictive model relating daily fluctuations in summer temperatures and mortality rates. BMC Public Health, 7, 1-11, doi:10.1186/1471-2458-7-114.

Friedman, J. H., 1991: Multivariate adaptive regression splines. Ann. Stat., 19, 1-67, doi:10.1214/ aos/1176347963.

—, and C. B. Roosen, 1995: An introduction to multivariate adaptive regression splines. Stat. Methods Med. Res., 4, 197-217, doi:10.1177/096228029500400303.

Gessner, U., V. Naeimi, I. Klein, C. Kuenzer, D. Klein, and S. Dech, 2013: The relationship between precipitation anomalies and satellite-derived vegetation activity in central Asia. Global Planet. Change, 110A, 74-87, doi:10.1016/j.gloplacha.2012.09.007.

Hargrove, W., and F. Hoffman, 2004: Potential of multivariate quantitative methods for delineation and visualization of ecoregions. Environ. Manage., 34, S39-S60, doi:10.1007/ s00267-003-1084-0.

Henebry, G. M., 2003: Grasslands of the North American Great Plains. Phenology: An Integrative Environmental Science, M. D. Schwartz, Ed., Tasks for Vegetation Science Series, Vol. 39, Springer, 157-174.

Hermance, J. F., D. J. Augustine, and J. D. Derner, 2015: Quantifying characteristic growth dynamics in a semi-arid grassland ecosystem by predicting short-term NDVI phenology from daily rainfall: A simple four parameter coupled-reservoir model. Int. J. Remote Sens., 36, 5637-5663, doi:10.1080/01431161.2015.1103916.

Hodges, T., 1991: Predicting Crop Phenology. CRC Press, 233 pp.

Jenkerson, C., T. Maiersperger, and G. Schmidt, 2010: eMODIS: A user-friendly data source. U.S. Department of the Interior, U.S. Geological Survey Open-File Rep. 2010-1055, 22 pp. [Available online at https://pubs.usgs.gov/of/2010/1055/pdf/OF2010-1055.pdf.]

Ji, L., and A. J. Peters, 2004: Forecasting vegetation greenness with satellite and climate data. IEEE Geosci. Remote Sens. Lett., 1, 3-6, doi:10.1109/LGRS.2003.821264.

- B. Wylie, B. Ramachandran, and C. Jenkerson, 2010: A comparative analysis of three different MODIS NDVI datasets for Alaska and adjacent Canada. Can. J. Remote Sens., 36, S149-S167, doi:10.5589/m10-015.

Jolly, W. M., R. Nemani, and S. W. Running, 2005: A generalized, bioclimatic index to predict foliar phenology in response to climate. Global Change Biol., 11, 619-632, doi:10.1111/ j.1365-2486.2005.00930.x.

Jonsson, P., and L. Eklundh, 2002: Seasonality extraction by function fitting to time-series of satellite sensor data. IEEE Trans. Geosci. Remote Sens., 40, 1824-1832, doi:10.1109/ TGRS.2002.802519.

Jorgensen, S. E., 2009: Ecosystem Ecology. Elsevier, 521 pp.

Kogan, F. N., 1990: Remote sensing of weather impacts on vegetation in non-homogeneous areas. Int. J. Remote Sens., 11, 1405-1419, doi:10.1080/01431169008955102.

Lambers, H., T. L. Pons, and F. S. Chapin, 2008: Plant Physiological Ecology. Springer, 604 pp.

Larcher, W., 2003: Physiological Plant Ecology: Ecophysiology and Stress Physiology of Functional Groups. Springer, 513 pp.

Leathwick, J. R., J. Elith, and T. Hastie, 2006: Comparative performance of generalized additive models and multivariate adaptive regression splines for statistical modelling of species distributions. Ecol. Modell., 199, 188-196, doi:10.1016/j.ecolmode1.2006.05.022.

Lin, C., and N. Dugarsuren, 2015: Deriving the spatiotemporal NPP pattern in terrestrial ecosystems of Mongolia using MODIS imagery. Photogramm. Eng. Remote Sensing, 81, 587-598, doi:10.14358/PERS.81.7.587.

Menzel, A., 2003: Plant phenological anomalies in Germany and their relation to air temperature and NAO. Climatic Change, 57, 243-263, doi:10.1023/A:1022880418362. 


\section{Earth Interactions • Volume 21 (2017) • Paper No. 1 • Page 24}

Miller, P., W. Lanier, and S. Brandt, 2001: Using growing degree days to predict plant stages. Montana State University Extensive Service Montguide MT200103 AG 7/2001, 8 pp. [Available online at http://store.msuextension.org/publications/agandnaturalresources/ mt200103ag.pdf.]

Moulin, S., L. Kergoat, N. Viovy, and G. Dedieu, 1997: Global-scale assessment of vegetation phenology using NOAA/AVHRR satellite measurements. J. Climate, 10, 1154-1170, doi:10.1175/1520-0442(1997)010<1154:GSAOVP>2.0.CO;2.

Muñoz-Díaz, D., and F. S. Rodrigo, 2006: Seasonal rainfall variations in Spain (19122000) and their links to atmospheric circulation. Atmos. Res., 81, 94-110, doi:10.1016/j.atmosres.2005.11.005.

NASA Ames Ecological Forecasting Laboratory, 2009: Ecocast: Monitoring, modeling, and forecasting ecosystem change. NASA, accessed 11 May 2016. [Available online at http:// ecocast.arc.nasa.gov/.]

Neyman, J., 1934: On the two different aspects of the representative method: The method of stratified sampling and the method of purposive selection. J. Roy. Stat. Soc., 97, 558-606, doi: $10.2307 / 2342192$.

NGA, 1996: Digital terrain elevation data level 0. National Geospatial-Intelligence Agency Doc. MIL-PRF-89020A, 41 pp. [Available online at http://earth-info.nga.mil/publications/specs/ printed/89020A/89020A_DTED.pdf.]

Pau, S., E. M. Wolkovich, B. I. Cook, T. J. Davies, N. J. B. Kraft, K. Bolmgren, J. L. Betancourt, and E. E. Cleland, 2011: Predicting phenology by integrating ecology, evolution and climate science. Global Change Biol., 17, 3633-3643, doi:10.1111/ j.1365-2486.2011.02515.x.

Peñuelas, J., and Coauthors, 2004: Complex spatiotemporal phenological shifts as a response to rainfall changes. New Phytol., 161, 837-846, doi:10.1111/j.1469-8137.2004.01003.x.

Pfafflin, J. R., and E. N. Ziegler, 2006: Encyclopedia of Environmental Science and Engineering: Volumes One and Two. 5th ed. Taylor \& Francis, 1440 pp.

Piao, S., A. Mohammat, J. Fang, Q. Cai, and J. Feng, 2006: NDVI-based increase in growth of temperate grasslands and its responses to climate changes in China. Global Environ. Change, 16, 340-348, doi:10.1016/j.gloenvcha.2006.02.002.

Pickup, G., G. N. Bastin, and V. H. Chewings, 1994: Remote-sensing-based condition assessment for nonequilibrium rangelands under large-scale commercial grazing. Ecol. Appl., 4, 497517, doi:10.2307/1941952.

Post, E. S., and D. W. Inouye, 2008: Phenology: Response, driver, and integrator. Ecology, 89, 319 320, doi:10.1890/07-1022.1.

Prins, H. H. T., and P. E. Loth, 1988: Rainfall patterns as background to plant phenology in northern Tanzania. J. Biogeogr., 15, 451-463, doi:10.2307/2845275.

PRISM Climate Group, 2010: PRISM Climate Data. PRISM Climate Group, Oregon State University, accessed 3 April 2010. [Available online at http://www.prism.oregonstate.edu/.]

Pugnaire, F. I., and F. Valladares, 1999: Handbook of Functional Plant Ecology. M. Dekker, 901 pp.

R Core Team, 2015: R: A language and environment for statistical computing. R Foundation for Statistical Computing, accessed 23 January 2015. [Available online at https://www.R-project.org/.]

Reed, B. C., J. F. Brown, D. VanderZee, T. R. Loveland, J. W. Merchant, and D. O. Ohlen, 1994: Measuring phenological variability from satellite imagery. J. Veg. Sci., 5, 703-714, doi: $10.2307 / 3235884$.

Schuster, W. S., D. L. Alles, and J. B. Mitton, 1989: Gene flow in limber pine: Evidence from pollination phenology and genetic differentiation along an elevational transect. Amer. J. Bot., 76, 1395-1403, doi:10.2307/2444563.

Schwartz, M. D., 2003a: Introduction. Phenology: An Integrative Environmental Science, M. D. Schwartz, Ed., Tasks for Vegetation Science Series, Vol. 39, Springer, 3-7.

- 2003b: Phenoclimatic measures. Phenology: An Integrative Environmental Science, M. D. Schwartz, Ed., Tasks for Vegetation Science Series, Vol. 39, Springer, 331-343. 


\section{Earth Interactions • Volume 21 (2017) • Paper No. 1 • Page 25}

Sharma, P. D., 2005: Ecology and Environment. Rastogi Publications, 640 pp.

Shen, M., and Coauthors, 2014: Earlier-season vegetation has greater temperature sensitivity of spring phenology in Northern Hemisphere. PLoS One, 9, e88178, doi:10.1371/ journal.pone.0088178.

Sparks, T. H., and P. D. Carey, 1995: The responses of species to climate over two centuries: An analysis of the Marsham phenological record, 1736-1947. J. Ecol., 83, 321-329, doi:10.2307/2261570.

— — - and J. Combes, 1997: First leafing dates of trees in Surrey between 1947 and 1996. London Nat., 76, 15-20.

— E. P. Jeffree, and C. E. Jeffree, 2000: An examination of the relationship between flowering times and temperature at the national scale using long-term phenological records from the UK. Int. J. Biometeor., 44, 82-87, doi:10.1007/s004840000049.

Srivastava, L. M., 2002: Plant Growth and Development: Hormones and Environment. Academic Press, $772 \mathrm{pp}$.

Stohlgren, T. J., P. Ma, S. Kumar, M. Rocca, J. T. Morisette, C. S. Jarnevich, and N. Benson, 2010: Ensemble habitat mapping of invasive plant species. Risk Anal., 30, 224-235, doi:10.1111/ j.1539-6924.2009.01343.x.

Suzuki, R., S. Tanaka, and T. Yasunari, 2000: Relationships between meridional profiles of satellitederived vegetation index (NDVI) and climate over Siberia. Int. J. Climatol., 20, 955-967, doi:10.1002/1097-0088(200007)20:9<955::AID-JOC512>3.0.CO;2-1.

Tang, H., Z. Li, Z. Zhu, B. Chen, B. Zhang, and X. Xin, 2015: Variability and climate change trend in vegetation phenology of recent decades in the Greater Khingan Mountain area, northeastern China. Remote Sens., 7, 11 914-11 932, doi:10.3390/rs70911914.

Thornton, P. E., M. M. Thornton, B. W. Mayer, N. Wilhelmi, Y. Wei, and R. B. Cook, 2012: Daymet: Daily surface weather on a 1-km grid for North America,1980 - 2011. Oak Ridge National Laboratory Distributed Active Archive Center, accessed 26 February 2013. [Available online at http://daymet.ornl.gov/.]

Timmermans, M., 2010: Plant Development. Academic Press, 480 pp.

USGS, 1997: STATSGO soil characteristics for the conterminous United States, accessed 15 March 2009. [Available online at https://water.usgs.gov/GIS/metadata/usgswrd/XML/muid.xml.]

_ 2010: National gap analysis program land cover data, accessed 8 October 2011. [Available online at https://gapanalysis.usgs.gov/gaplandcover/.]

Van Dyke, F., 2008: Conservation Biology: Foundations, Concepts, Applications. Springer, 477 pp.

Van Leeuwen, W. J., 2008: Monitoring the effects of forest restoration treatments on post-fire vegetation recovery with MODIS multitemporal data. Sensors, 8, 2017-2042, doi:10.3390/s8032017.

Villordon, A., C. Clark, D. Ferrin, and D. LaBonte, 2009: Using growing degree days, agrometeorological variables, linear regression, and data mining methods to help improve prediction of sweetpotato harvest date in Louisiana. HortTechnology, 19, 133-144.

Walter, H., and J. Wieser, 1973: Vegetation of the Earth in Relation to Climate and the EcoPhysiological Conditions. English Universities Press, 237 pp.

Waugh, D., 2000: Geography: An Integrated Approach. Nelson Thornes, 657 pp.

White, M. A., and R. R. Nemani, 2006: Real-time monitoring and short-term forecasting of land surface phenology. Remote Sens. Environ., 104, 43-49, doi:10.1016/j.rse.2006.04.014.

— , P. E. Thornton, and S. W. Running, 1997: A continental phenology model for monitoring vegetation responses to interannual climatic variability. Global Biogeochem. Cycles, 11, 217234, doi:10.1029/97GB00330.

— , F. Hoffman, W. W. Hargrove, and R. R. Nemani, 2005: A global framework for monitoring phenological responses to climate change. Geophys. Res. Lett., 32, L04705, doi:10.1029/ 2004GL021961.

Whittaker, R. H., 1970: Communities and Ecosystems. Macmillan, 162 pp.

Wielgolaski, F. E., and D. W. Inouye, 2003: High latitude climates. Phenology: An Integrative Environmental Science, M. D. Schwartz, Ed., Tasks for Vegetation Science Series, Vol. 39, Springer, 175-194. 


\section{Earth Interactions - Volume 21 (2017) • Paper No. 1 • Page 26}

Woodward, F. I., 1987: Climate and Plant Distribution. Cambridge University Press, 174 pp.

Xie, Y., A. Zhang, and W. Welsh, 2015: Mapping wetlands and phragmites using publically available remotely sensed images. Photogramm. Eng. Remote Sensing, 81, 69-78, doi:10.14358/PERS.81.1.69.

Yang, W., L. Yang, and J. Merchant, 1997: An assessment of AVHRR/NDVI-ecoclimatological relations in Nebraska, USA. Int. J. Remote Sens., 18, 2161-2180, doi:10.1080/ 014311697217819.

$\mathrm{Yu}, \mathrm{H}$., E. Luedeling, and J. Xu, 2010: Winter and spring warming result in delayed spring phenology on the Tibetan Plateau. Proc. Natl. Acad. Sci. USA, 107, 22 151-22 156, doi:10.1073/ pnas. 1012490107.

Zhang, X., J. C. F. Hodges, C. B. Schaaf, M. A. Friedl, A. H. Strahler, and G. Feng, 2001: Global vegetation phenology from AVHRR and MODIS data. Proc. IEEE 2001 Int. Geoscience and Remote Sensing Symp. IGARSS '01, Vol. 2265, Sydney, Australia, IEEE, 2262-2264, doi:10.1109/IGARSS.2001.977969.

—, M. A. Friedl, C. B. Schaaf, A. H. Strahler, J. C. F. Hodges, F. Gao, B. C. Reed, and A. Huete, 2003: Monitoring vegetation phenology using MODIS. Remote Sens. Environ., 84, 471-475, doi:10.1016/S0034-4257(02)00135-9.

- , - and - 2009: Sensitivity of vegetation phenology detection to the temporal resolution of satellite data. Int. J. Remote Sens., 30, 2061-2074, doi:10.1080/ 01431160802549237.

Zhang, Y., G. F. Hepner, and P. E. Dennison, 2012: Delineation of phenoregions in geographically diverse regions using $k$-means ++ clustering: A case study in the upper Colorado River basin. GIsci. Remote Sens., 49, 163-181.

Earth Interactions is published jointly by the American Meteorological Society, the American Geophysical Union, and the Association of American Geographers. Permission to use figures, tables, and brief excerpts from this journal in scientific and educational works is hereby granted provided that the source is acknowledged. Any use of material in this journal that is determined to be "fair use" under Section 107 or that satisfies the conditions specified in Section 108 of the U.S. Copyright Law (17 USC, as revised by P.IL. 94553) does not require the publishers' permission. For permission for any other from of copying, contact one of the copublishing societies. 